www.jmscr.igmpublication.org

Index Copernicus Value: 79.54

ISSN (e)-2347-176x ISSN (p) 2455-0450

crossref DOI: https://dx.doi.org/10.18535/jmscr/v7i5.108

\title{
Use of oral midazolam as a premedication in patients undergoing diagnostic UGI Endoscopy: A double blind placebo controlled randomized trial
}

\author{
Authors \\ Dr Mamta Sharma ${ }^{1}$, Dr Anil Sharma ${ }^{2 *}$ \\ ${ }^{1}$ Assistant Professor Anesthesiology, Govt. Medical College, Kota \\ ${ }^{2}$ Assistant Professor Gastroenterology, Govt. Medical College, Kota \\ *Corresponding Author \\ Dr Anil Sharma
}

Assistant Professor Gastroenterology, Govt. Medical College, Kota, India

\begin{abstract}
Introduction: To investigate the safety and efficacy of oral midazolam as premedication for patients undergoing upper GI endoscopy, A double blind placebo controlled randomized trial was conducted.

Methods: A total of 150 patients were randomized to receive either $7.5 \mathrm{mg}$ oral midazolam $(n=75)$ or a placebo $(n=75)$ as premedication in patients undergoing upper GI endoscopy. Primary outcome measure was anxiety score (visual analog scale) during procedure. Secondary outcome measures were overall tolerance, extent of amnesia, patient willingness to repeat the procedure and hemodynamic changes after medication.

Result: The median anxiety score during the procedure in the midazolam group was significantly lower than in the control group (1.8 vs. 3.6). A significantly higher number of patients in the midzolam group graded overall tolerance as excellent or good as compared to control group (72\% vs. 48\%). A significantly higher number of patients in the midazolam group reported a partial to complete amnesia response as compared to control (52\% vs.32\%). Patients in the midazolam group were more willing to repeat the procedure if necessary ( $88 \%$ vs. 64\%). There was no statistically significant difference in hemodynamic changes between groups.

Conclusions: Oral administration of midazolam as premedication is safe and effective method of sedation that significantly reduces anxiety and improves overall tolerance for patients undergoing upper GI endoscopy.
\end{abstract}

\section{Introduction}

Most of the patients find esophagogastroduodenoscopy (EGD) an uncomfortable procedure. Midazolam a short acting benzodiazepine, due to its good ante grade amnesic effect is frequently used intravenously to induce conscious sedation in patients undergoing EGD $^{1}$. The efficacy of its effect has been very well demonstrated. ${ }^{2-5}$ However IV administration of sedative drugs for outpatient EGD have been related to certain risks like respiratory depression, hypotension etc ${ }^{1,6}$. To manage them effectively require trained personnel, well equipped recovery facilities, close patient monitoring adding extra burden on health care professionals and it is not that ideal for office based procedure like EGD. 
In our setup, patients undergoing EGD are not given sedative agents due to large patient load. Since IV administrations of sedative agent have lot of risks, oral administration of sedation is an alternative for outpatient $\mathrm{EGD}^{7-11}$. Oral administration being safe, effective and devoid of many disadvantages, has been shown to be useful in premedication for other endoscopic procedure 12-13. Use of oral midazolam in Indian patients undergoing EGD has not been studied extensively. This randomized placebo controlled trial performed to assess the use of oral midazolam as premedication for adults undergoing effective EGD.

\section{Patients and Methods}

This prospective study was conducted in government medical college, endoscopy centre from September 2018 to November 2018. Patients between the ages of 18 years to 70 years who were scheduled for elective diagnostic EGD and considered by American society of anesthesia (ASA) criteria to be class 1 to 2 were considered eligible for inclusion. Exclusion criteria werehaving history of esophagectomy, gastrectomy, surgery on the upper gi tract, ASA class 3 to 4, alcoholism, pregnancy, patient on antipsychotic drugs and patient allergic to midazolam. All patients were advised not to drive and perform mechanical work for remaining day after ingestion of medication. The study was approved by the research ethics committee and consent was taken from every patient.

Demographic data including age, sex, body weight, education level, baseline vital signs and anxiety score (10 cm visual analogue scale: 0 , no anxiety to 10 , extreme anxiety) were collected. Patients were randomly selected to take $7.5 \mathrm{mg}$ of midazolam in tablet form (midazolam group- MG) or a placebo (control group-CG) as premedication $20 \mathrm{~min}$ before EGD procedure.

All the participants in the trial were blinded to the treatment modality. After ingestion of medicine every patient was monitored continuously for pulse and oxygen saturation and blood pleasure were recorded before the procedure and every five minutes after EGD until recovery. EGD was performed twenty minutes after ingestion of medicine. Topical pharyngeal anesthesia was given with lidocaine spray before procedure. EGD was performed by pentax EG-290Kp gastroscope. A preprocedure anxiety score was obtained by using $10 \mathrm{~cm}$ unscaled visual analogue scale. Additional requirement of oxygen and sedation during procedure were noted. After the procedure every patient remained in recovery room until fully recovered. Full recovery was defined as hemodynamic stability and orientation to time, place and person. After the patient fully recovered a questionnaire was used to asses anxiety during EGD (10cm unscaled VAS), overall tolerance of the procedure, the extent of amnesia and willingness to repeat the procedure.

\section{Table no.1}

\begin{tabular}{|c|l|}
\hline Amnesia score & Definition \\
\hline 1 & Patient not able to recall any part of procedure \\
\hline 2 & Able to recall and describe some part of procedure \\
\hline 3 & Able to recall and describe most part of procedure \\
\hline 4 & Able to recall and describe entire procedure \\
\hline
\end{tabular}

Table no.2 Patient rating for tolerance of EGD

\begin{tabular}{|l|l|l|}
\hline S.no. & Tolerance & Definition \\
\hline 1 & EXCELLENT & Believe that procedure was comfortable, no additional sedation was required \\
\hline 2 & GOOD & $\begin{array}{l}\text { Believe that procedure was generally comfortable, there were part of procedure } \\
\text { during which sedation could have been given }\end{array}$ \\
\hline 3 & FAIR & Uncomfortable during most of procedure \\
\hline 4 & POOR & Very Uncomfortable during entire procedure \\
\hline
\end{tabular}


The primary outcome was the anxiety score during EGD. Secondary outcomes were overall tolerance, extent of amnesia, patient willingness to repeat the procedure and episode of hypotension (systolic blood pressure $<90 \mathrm{~mm} \mathrm{hg}$ ) and desaturation (arterial oxygen saturation <90\%)

\section{Statistical methods}

Statistical analysis was performed with a statistical software package- SPSS. Comparisons were carried out by the pearson chi-square test where appropriate for categorical data, the student $t$ test for parametric data and mann-whitney u test for non parametric data. A two sided $\mathrm{p}$ value < 0.05 was considered significant.

Table -3 Patient characteristics

\begin{tabular}{|c|c|c|c|}
\hline & $\begin{array}{l}\text { MIDAZOLAM } \\
\text { GROUP }(\mathrm{N}=75)\end{array}$ & $\begin{array}{c}\text { PLACEBO } \\
\text { GROUP }(\mathrm{N}=75)\end{array}$ & $\mathrm{p}$ VALUE \\
\hline Age (years)* & $45(7.5)$ & $43.5(8.2)$ & $>0.05$ \\
\hline Gender (M:F) & $41: 34$ & $46: 29$ & $>0.05$ \\
\hline \multicolumn{4}{|l|}{ Education level } \\
\hline Primary $(\%)$ & $23(30.6)$ & $20(26.6)$ & $>0.05$ \\
\hline Secondary $(\%)$ & $40(52.0)$ & $42(56.0)$ & $>0.05$ \\
\hline Tertiary $(\%)$ & $12(16.0)$ & $13(17.3)$ & $>0.05$ \\
\hline Body weight $(\mathrm{kg}) * \mathrm{ff}$ & $56.5(12.2)$ & $51.3(10.3)$ & $>0.05$ \\
\hline \multicolumn{4}{|l|}{ Indication for EGD } \\
\hline Dyspepsia $(\%)$ & $27(36.0)$ & $25(33.3)$ & $>0.05$ \\
\hline GERD (\%) & $22(29.3)$ & $23(30.6)$ & $>0.05$ \\
\hline Epigastric pain $(\%)$ & $20(26.6)$ & $21(28.0)$ & $>0.05$ \\
\hline Anemia & $4(5.3)$ & $2(2.6)$ & \\
\hline Others & $2(2.6)$ & $4(5.3)$ & \\
\hline No. of patient with previous EGD (\%) & $23(30.6)$ & $25(33.3)$ & $>0.05$ \\
\hline Baseline anxiety score in VAS $f$ & $2.9(0.5-5.0)$ & $3.2(1.5-5.0)$ & $>0.05$ \\
\hline Baseline systolic blood pleasure(mmhg)* & $127(16.4)$ & $129(19.5)$ & $>0.05$ \\
\hline Baseline oxygen saturation $(\%)^{*}$ & $98(1.3)$ & $99(1.3)$ & $>0.05$ \\
\hline
\end{tabular}

VAS - Visual analog scales *mean (standard deviation) $f$ median (interquartile range IQR)

\section{Result}

A total of 172 patient were eligible during study period and out of these 22 were excluded because they refused to participate (17), unable to give consent because of difficulty in communication (5). The remaining 150 patient were randomized, 75 to each group of midazolam and placebo group. Baseline characteristics for patients of both group are shown in table 3. There was no statistically significant difference in the baseline and preprocedural anxiety score between the groups. The median anxiety score during the procedure was significantly lower in the midazolam group compared with the controlled group (1.8 [IQR 0-4.9] vs. 3.6 [IQR 2.0-7.8] p $<0.05)$. Patient in midazolam group were significantly more likely to rank overall tolerance as excellent or good then those randomized to control group ( $72 \% \mathrm{v} / \mathrm{s} 48 \%) \mathrm{p}<0.05$.

Table no. 4: Results

\begin{tabular}{|l|c|c|c|}
\hline & $\begin{array}{c}\text { Midazolam group } \\
\mathrm{MG}(\mathrm{N}=75)\end{array}$ & $\begin{array}{c}\text { Control group } \\
\text { CG (N=75) }\end{array}$ & P Value \\
\hline Median anxiety score before procedure (interquertile range) & $0.7(0-2.2)$ & $1.0(0.20-2.1)$ & $>0.05$ \\
\hline $\begin{array}{l}\text { Median anxiety score during procedure } \\
\text { (interquartile range) }\end{array}$ & $1.8(0-4.9)$ & $3.6(2.0-7.8)$ & $<0.05$ \\
\hline Tolerance to procedure & & & \\
\hline Excellent or good & $54(72 \%)$ & $36(48 \%)$ & $<0.05$ \\
\hline Fair or poor & $21(28 \%)$ & $39(52 \%)$ & $<0.05$ \\
\hline Amnesia score & & & \\
\hline
\end{tabular}




\begin{tabular}{|l|c|c|c|}
\hline Partial to complete amnesia (sure 1+2+3) & $39(52 \%)$ & $24(32 \%)$ & $<0.05$ \\
\hline No amnesia & $36(48 \%)$ & $51(68 \%)$ & \\
\hline Willingness to repeat EGD (NO. OF PATIENT) & $66(88 \%)$ & $48(64 \%)$ & $<0.05$ \\
\hline Additional sedation(no.of patient) & 0 & $3(4 \%)$ & $<0.05$ \\
\hline Hypotension (SBP $<90 \mathrm{mmhg})$ & $3(4 \%)$ & $1(1.3 \%)$ & $<0.05$ \\
\hline Desaturation $(\mathrm{saO} 2<90 \%)$ & $2(2.6 \%)$ & $1(1.3 \%)$ & $<0.05$ \\
\hline
\end{tabular}

No patient in midazolam group required additional sedation, whereas patient in control group required midazolam to complete the procedure $(0 \%$ vs. $4 \%, \mathrm{p}<0.05)$. There was statistically significant difference in willingness to repeat, in MG vs. CG (88\% VS 64\% $\mathrm{P}<0.05)$. Significantly more people in midazolam group were willing to repeat procedure. More patient in the MG reported a partial to complete amnesia response as compare to $\mathrm{CG}(52 \%$ vs $32 \% \mathrm{p}<0.05)$. Hypotension developed in 3 patient $(4 \%)$ in $\mathrm{MG}$ group and 1 patient $(1.3 \%)$ in $\mathrm{CG}(\mathrm{P}>0.05)$. All episodes were transient and no treatment was required. Desaturation occurred in 2 patient (2.6\%) in MG and 1 patient in CG (1.3\%). All of these patients were treated effectively by administration of oxygen. All patients were able to leave the endoscopy room 30 minutes after procedure. One patient in MG complained of dizziness after discharge, only reassurance was required. No drug related side effects were observed.

\section{Discussion}

Many endoscopist perform EGD in unsedated patients, but a proportion of patient will benefit from sedative drug during the procedure ${ }^{14-15}$. The ideal sedative agent for short procedure should be safe, effective, easy to administer, rapid onset and recovery. Oral midazolam fulfill these qualities and it is widely used in both children and adult as a premedication to surgery ${ }^{16-17}$. Its use for endoscopy is not common in routine practice. Oral sedative agent for patient undergoing EGD has been shown to be useful ${ }^{7-10}$. Hedenbro et al ${ }^{(7)}$ used oral triazolam as premedication in adults undergoing EGD and found that it relieved patient discomfort during procedure. Oral lonazepam has been shown to improve patient discomfort during bronchoscopy ${ }^{13}$. In a study by kinganeswaran et $\mathrm{al}^{12}$ used a $7.5 \mathrm{mg}$ oral midazolam for sigmoidoscopy procedure and showed that this decreased pain and anxiety during the procedure. Study by likman mui et al. showed that oral midazolam administered to adults who undergo elective EGD, reduced anxiety and improve overall tolerance to the procedure ${ }^{20}$. Oral midazolam had good amnestic effect and it facilitates a repeat procedure if required. Oral midazolam appears to be safer than the intravenous sadative agents. In present study there was no significant difference between the two groups in term of hemodynamic stability. No patient required resuscitation. All patients in both groups were fully recovered within 30 minutes after procedure. These findings show that oral midazolam is safe and effective in patients undergoing EGD and can be used on routine basis especially in situation where intravenous sedation cannot be used.

Present study has several limitation as it did not include elderly patients with co morbid conditions in which unsedated EGD is more likely to successful due to reduced pharyngeal sensation ${ }^{18}$. Hence result may have been amplified. The safety profile is also different in elderly patients. Moreover ethnic difference in pain and stress perception may limit the generalization of result in other population. The optimal dosage and timing of administration of midazolam as premedication were not assessed. A dosage of $7.5 \mathrm{mg} 20$ minutes before EGD was taken because this was used in study by kuganeswaran et $\mathrm{al}^{12}$. No dose adjustment was made for individual patient; this $7.5 \mathrm{mg}$ dose of midazolam may be overdose for some patients and under dose for others.

After oral intake midazolam is rapidly and extensively absorbed from gut ${ }^{19}$. Mean absorption half life of oral midazolam is reported to be $0.23(0.37)$ hours. In most individuals, a peak drug 
level is achieved within one hour. In present study administration of midazolam, 20 minutes before procedure was adequate for most of the patients. For satisfactory sedation some patients may require longer time. Quantity of sedation achieved by oral vs. IV administration of midazolam is not known. With oral midazolam dose titration according to response and achieving an optimal level of sedation for each patient is very difficult. Further studies are required regarding this issue.

In conclusion, the result of this prospective randomized control trial shows that oral administration of midazolam to patients undergoing UGI endoscopy is safe and effective. Oral midazolam can be recommended as an alternative to IV administration of sedative drugs in endoscopy units where IV administration of sedative is not routines because this will improve patient tolerance for UGI endoscopies.

\section{References}

1. Quine MA, Bell GD, McCloy RF, Charlton JE, Devlin HB, Hopkins A. Prospective audit of upper gastrointestinal endoscopy in two regions of England: safety, staffing, and sedation methods. Gut 1995;36:462-7.

2. Froehlich F, Schwizer W, Thorens J, Kohler M, Gonvers JJ, Fried M. Conscious sedation for gastroscopy: patient tolerance and cardiorespiratory parameters. Gastroenterology 1995;108:697-704.

3. Christe C, Janssens JP, Armenian B, Hermann F, Vogt N. Midazolam sedation for upper gastrointestinal endoscopy in older persons: a randomized, double-blind, placebo-controlled study. J Am Geriatr Soc 2000;48:1398-403.

4. Laluna L, Allen ML, Dimarino AJ Jr. The comparison of midazolam and topical lidocaine spray versus the combination of midazolam, meperidine, and topical lidocaine spray to sedate patients for upper endoscopy. Gastrointest Endosc 2001;53:289-93.
5. Bell GD, Spickett GP, Reeve PA, Morden A, Logan RF. Intravenous midazolam for upper gastrointestinal endoscopy: a study of 800 consecutive cases relating dose to age and sex of patient. $\mathrm{Br} \mathrm{J}$ Clin Pharmacol 1987;23:241-3.

6. Thompson AM, Wright DJ, Murray W, Ritchie GL, Burton HD,Stonebridge PA. Analysis of 153 deaths after upper gastrointestinal endoscopy: room for improvement? Surg Endosc 2004;18:22-5.

7. Hedenbro JL, Ekelund M, Aberg T, Lindblom A. Oral sedation for diagnostic upper endoscopy. Endoscopy 1991;23:810.

8. McHenry R, Crabb D, Brunelle R, Lehman GA. Oral medications for upper gastrointestinal endoscopy using small diameter endoscope. Gastrointest Endosc 1998;34:327-31.

9. Douglas JG, Nimmo WS, Wanlesss R, Jarvie DR, Heading RC, Finlayson ND. Sedation for upper gastro-intestinal endoscopy. A comparison oral temazepam and i.v. diazepam. $\mathrm{Br} \mathrm{J}$ Anaesth 1980;52:811-5.

10. Liacouras CA, Mascarenhas M, Poon C, Wenner WJ. Placebo-controlled trial assessing the use of oral midazolam as premedication to conscious sedation for pediatric endoscopy. Gastrointest Endosc 1998;47:455-60.

11. Martinez JL, Sutters KA, Waite S, Davis J, Median E, Montano N, et al. A comparison of oral diazepam versus midazolam, administered with intravenous meperidine, as premedication to sedation for pediatric endoscopy. J Pediatr Gastroenterol Nutr 1997;25:261-6.

12. Kuganeswaran E, Clarkston WK, Cuddy PG, Quiason SG, Pandya PK, Dierenfeldt WT, et al. A double-blind placebo controlled trial of oral midazolam as premedication before flexible sigmoi- 
doscopy. Am J Gastroenterol 1999;94:3215-9.

13. Maltais F, Laberge F, Laviolette M. A randomized double-blind, placebocontrolled study of lorazepam as premedication for bronchoscopy. Chest 1996;109:1195-8.

14. Al-Atrakchi HA. Upper gastrointestinal endoscopy without sedation: a prospective study of 2000 examinations. Gastrointest Endosc 1989; 35:79-81.

15. Fisher NC, Bailey S, Gibson JA. A prospective, randomized controlled trial of sedation vs. no sedation in outpatient diagnostic upper gastrointestinal endoscopy. Endoscopy 1998;30:21-4.

16. Mccluskey A, Meakin GH. Oral administration of midazolam as premedicant for paediatric day-case anesthesia. Anesthesia 1994;49: 782-5.

17. Kikuchi K, Konishia P, Watanabe Y. Efficacy of oral midazolam as premedication in adult. Masui-Jap J Anesthiol 1994;43:1824-7.

18. Abraham N, Barkun A,Larocque M, Fallone C, Mayrand S, Baffis V, et al. Predicting which patients undergoing upper endoscopy comfortably without conscious sedation.Gastrointest Endos 2002;56:180-9.

19. Smith MT, Eadie MJ, Brophy TO. The pharmacokinetics of midazolam in man. Eur J Clin Pharmacol 1981;19:271-8.

20. Mui, L-M., Teoh, A.Y.B., Ng, E.K.W. et al. Premedication with orally administered midazolam in adults undergoing diagnostic upper endoscopy: a double-blind placebocontrolled randomized trial. Gastrointest Endosc. 2005; 61: 195-200. 